\title{
Galerkin's formulation of the finite elements method to obtain the depth of closure
}

\author{
L. Aragonés ${ }^{\mathrm{a}, *}$, J.I. Pagán ${ }^{\mathrm{a}}$, I. López ${ }^{\mathrm{a}}$, F.J. Navarro-González ${ }^{\mathrm{b}}$, Y. Villacampa ${ }^{\mathrm{b}}$ \\ ${ }^{a}$ Dept. of Civil Engineering, University of Alicante, Carretera San Vicent del Raspeig s/n, 03690 Alicante, Spain \\ ${ }^{\mathrm{b}}$ Dept. of Applied Mathematics, University of Alicante, Carretera San Vicent del Raspeig s/n, 03690 Alicante, Spain
}

\section{A R T I C L E IN F O}

\section{Article history:}

Received 9 August 2018

Received in revised form 2 January 2019

Accepted 3 January 2019

Available online $\mathrm{xxx}$

Editor: Damia Barcelo

Keywords:

Depth of closure

Sediment

Galerkin

Numerical model

Posidonia oceanica

\begin{abstract}
A B S T R A C T
Coastal erosion and lack of sediment supply are a serious global problem. It is therefore necessary to determine the depth of closure (DoC) of a beach-key parameter in the calculation of the sand volume and the location of the beach protection elements - in a precise way. For this reason, this work generates a numerical model based on Galerkin's formulation of finite elements that provides sufficient precision for the determination of DoC with a minimum investment. Thus, after the generation of three models in which the difference was the dependent variables, the least complex has been chosen. It is composed of the variables: median sediment size, wave height and period associated with the mean flow, as well as the angle that the mean flow forms with respect to the studied profile in absolute value $(\alpha)$. The selected model has been compared with the most commonly used models currently in use, having an average absolute error of $0.36 \mathrm{~m}$ and an average MAPE of $<7.5 \%$, which represents an improvement of $>70 \%$ over current models. In addition, it presents a high stability, since after the random disturbance of all the input variables (up to 5\%), the model error remains stable, increasing the MAPE by a maximum of $7.4 \%$ and the average absolute error by $0.15 \mathrm{~m}$. Therefore, it is possible to use the model to infer the DoC in other study areas where the values of the variables are similar to those studied here, although the selected method can be extrapolated to other parts of the world.
\end{abstract}

\section{Introduction}

Coastal erosion is a major global problem (Allen, 1981; Pranzini et al., 2015; Semeoshenkova and Newton, 2015). To try to solve this problem, hard solutions (construction of jetties, dikes, etc.) and/or soft solutions (sand dumping) are used (Crain et al., 1995; Hamm et al., 2002). Over the last few decades, there has been a gradual shift in coastal defence techniques, tending in recent years to soft actions (Dean, 2002; Trembanis and Pilkey, 1998). The supply of sand to the beach is considered by many authors/engineers to be the most acceptable way to stabilize the coast. However, the scarcity of sand in the world makes necessary to accurately calculate the volume required for the nourishment of a beach (Aragonés et al., 2016a).

In this regard, the concept of Depth of Closure (DoC) is of the utmost importance for coastal management and engineering. In fact, $\mathrm{DoC}$ is fundamental in many areas, for instance, to assess sediment balance, investigate shoreface morphodynamics, identify the active zone for beach nourishment, and/or model coastal evolution (Garcia et al., 2017). DoC is defined as the depth to which the hydrodynamic processes at the bottom of the sea will be sufficiently weak to make changes in depth over time "negligible" for the purpose considered (Nicholls et al., 1998). The definition of "negligible" is specific to the purpose and therefore different criteria can be used to define the DoC. It is commonly considered to be the morphodynamic boundary separating an active region to the land from an inactive region to the sea (Hinton and Nicholls, 1998). Other authors consider DoC to be

\footnotetext{
* Corresponding author.

Email address: laragones@ua.es (L. Aragonés)
}

similar to the depth beyond which the transport of sediments through the waves is practically nil, and therefore the term "depth without movement" is more appropriate (Phillips and Williams, 2007).

The first theoretical definition of DoC came from a study conducted by Hallermeier $(1981,1978)$ using wave tank and field data. The inner DoC marks the seaward extent of the littoral zone, which is characterized by increased bed stresses and sediment transport due to waves near breaking and fluid circulation (Hallermeier, 1978). The outer DoC is the seaward limit of the offshore zone, where wave shoaling is the dominant process and bed agitation remains relatively moderate (Hallermeier, 1978).

Given the importance of this concept, several methods have been developed for its calculation. There are methods based on mathematical models (Dette et al., 2002; Larson and Hanson, 1996; Walstra et al., 2001), others that take into account the deviation between the actual profile and the equilibrium profile (Dean, 2002; Dean et al., 1993), and methods based on "in situ" measurements (Marsh et al., 1998). However, these systems fall into disuse nowadays. The most commonly used methods for the calculation of DoC are currently: i) Analytical or predictive formulations (Birkemeier, 1985; Hallermeier, 1981, 1978; Nicholls et al., 1996; Nicholls et al., 1998) derived from the proposal by Hallermeier (1978), in which the DoC is related to the characteristics of the incident waves in the study area. ii) Methods based on the comparative study of different profiles surveys over a certain period of time (Hinton and Nicholls, 1998; Nicholls et al., 1996). iii) Methods based on the evolution of sedimentology along the cross-shore beach profile. Among these methods is the one proposed by Niedoroda et al. (1985) that focuses on the distribution of the median sediment size $\left(\mathrm{D}_{50}\right)$ along the profile, or more recently, the method proposed by Aragonés et al. (2018) according to which 
the $\mathrm{D}_{50}$ decreases along the profile until the size increases again. The point of the minimum $\mathrm{D}_{50}$ value corresponds to the DoC.

However, the most accurate methods have some drawbacks. Comparative analysis of beach profiles requires many years of surveys in order to evaluate DoC. Sediment based methods, even those which only needs one sampling campaign, are expensive. For this reason, the aim of this work is to develop a numerical model to calculate the DoC using easily obtainable parameters. The diverse variables that can affect the location of the DoC, such as wave energy or sedimentology, are analysed, looking for possible relationships between these variables and the DoC.

\section{Study area}

The study area includes the sandy coast of the provinces of Valencia and Alicante (Spain). The province of Valencia is located in the east of the Iberian Peninsula, in the Gulf of Valencia, which is the largest morphodynamic unit of the Spanish natural coastline with a length of $97 \mathrm{~km}$ (Fig. 1). While this coast is mainly formed by long sandy beaches, the coast of the province of Alicante is characterized by a certain geological and geomorphological variety. Rocky cliffs, gravel and sand beaches, as well as wetlands that run through almost the entire province and the prairies of Posidonia oceanica are present on the littoral. Only $106 \mathrm{~km}$ of beaches of the $244 \mathrm{~km}$ of coastline in this province have been studied, excluding the areas formed by rocky cliffs, which are located mainly in the northern part of the province. It should be noted that this is a micro tidal area, with astronomical tides ranging between 20 and $30 \mathrm{~cm}$. Together with the meteorological tides they can reach up to $75 \mathrm{~cm}$ (Ecolevante, 2006).

\section{Methodology}

Firstly, the procedure followed to obtain the sedimentological DoC in each of the beaches under study is described. Secondly, a description of how to obtain each of the variables that will intervene in the model is presented. Finally, the process of modelling and selecting the best model is described.

\subsection{DoC from sediments}

In order to determine the DoC from the sediment samples, the procedure described by Aragonés et al. (2018) was used. According to this method, the $\mathrm{DoC}$ is at the point in the profile where a change in the sediment trend occurs. That is, the size of the sediment usually tends to decrease from shoreline to offshore, but there is a point where the size of the sediment increases and then decreases again. The DoC is therefore at the point of lowest $\mathrm{D}_{50}$ before the increase. This point is also usually accompanied by a significant percentage of particles smaller than $0.063 \mathrm{~mm}$.

The bathymetry and sediment sample data from the "Estudio ecocartográfico de las provincias de Valencia y Alicante, (Ecolevante, 2006)" survey was used in this work. Bathymetry was obtained using two multibeam sound and a single beam sound, from the shoreline to $-40 \mathrm{~m}$ depth, with an accuracy of $\pm 15 \mathrm{~cm}$ (Ecolevante, 2006).

The sediment sampling survey was conducted during the summer of 2006 in transects perpendicular to the coastline throughout the study area (Fig. 1c). Each transect has at least 9 sampling stations located between 0 and $-15 \mathrm{~m}$ below sea level. A Van Veen dredge was used to collect a total of 5029 samples, one per sampling station. The distance between samples in each transect is $150 \mathrm{~m}$ on average from $0 \mathrm{~m}$ to $-10 \mathrm{~m}$ and $500 \mathrm{~m}$ from $-10 \mathrm{~m}$ to $-15 \mathrm{~m}$. The data were processed statistically based on the granulometries of each sample

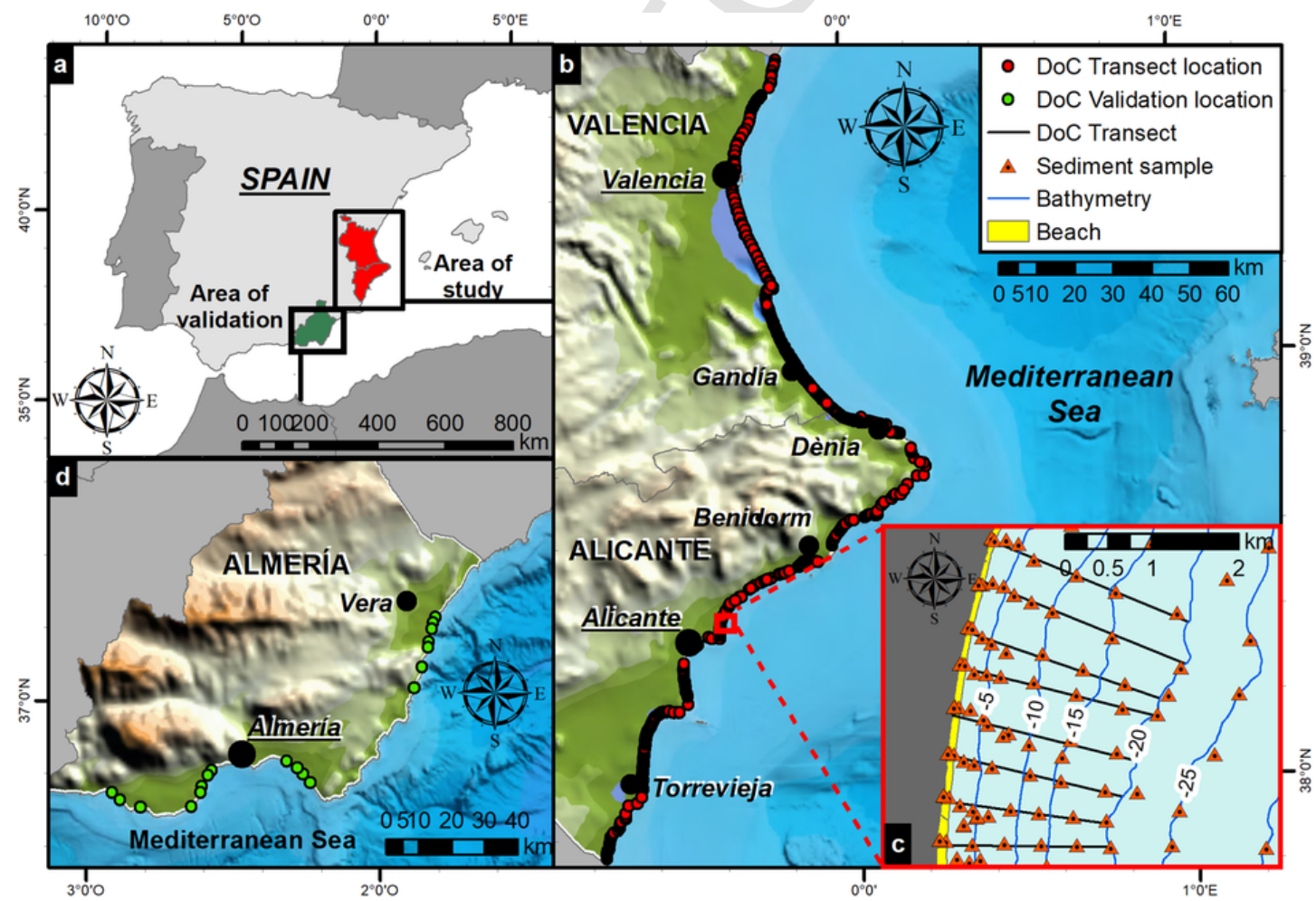

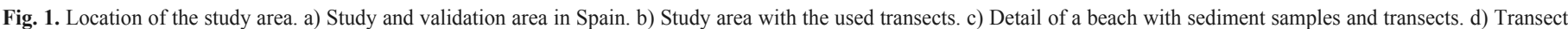
used for validation. 
and on the formulas of Folk and Ward (1957), and the corresponding median sediment size D50 was obtained for each location.

From the $\mathrm{D}_{50}$ data obtained, a continuous surface or map was created using the 3D Analyst extension of the ArcGIS suite, and the IDW (Inverse Distance Weighted) method to produce a grid of interpolated values of the $\mathrm{D}_{50}$. Finally, a total of 449 transects were created in the provinces of Valencia (227 transects) and Alicante (222 transects), which contained information of the cross-shore profile and the median sediment size. Analysing these profiles, the DoC was obtained following the procedure of Aragonés et al. (2018) described above.

\subsection{Maritime climate}

To obtain the parameters that characterise the maritime climate, data from three buoys provided by Puertos del Estado (www.puertos. es) were used. The Valencia 2630 buoy (39.516N 0.205E, $260 \mathrm{~m}$ deep) was used to study the waves of the entire province of Valencia and the northern area of Alicante (from the provincial border to the Cabo de la Nao). From Cabo de la Nao to Cabo de Santa Pola, the Alicante coastal buoy $1616(38.250 \mathrm{~N}-0.410 \mathrm{E}$, at a depth of $52 \mathrm{~m})$ was used. For the southern part of the province of Alicante (from Cabo de Santa Pola to the southern limit of the province) data from the Cabo de Palos 2610 buoy $(37.651 \mathrm{~N}-0.327 \mathrm{E}$, at a depth of $230 \mathrm{~m})$ were used.

Once the wave series were obtained for each of the buoys, the mean incident flow in each of the studied profiles was obtained. Thus, the wave height and the period corresponding to the mean flow and the angle formed between the mean flow and the corresponding profile were calculated.

$P$. oceanica meadows affect marine dynamics by reducing wave energy due to the friction of the leaf beams with the water and by the retention of sediments. To consider the effect on the waves, the energy reduction coefficient $\left(\mathrm{K}_{\mathrm{v}}\right)$ was calculated. For this purpose, the formulation proposed by Mendez and Losada (2004) and the values of the parameters $\alpha=0.1, \beta=2100$ and $\gamma=1.0$ (depending on the flexibility characteristics of the plants) proposed by Koftis and Prinos (2012) were used, as they are the ones that best adapt to the conditions of the study area according to Aragonés et al. (2017).

\subsection{Sedimentology}

The sedimentology of the beach was analysed through the median sediment size $\left(\mathrm{D}_{50}\right)$. Two data sources have been used for this purpose: i) Sedimentological samples collected by the University of Alicante in the years 2012 and 2013-a minimum of 4 samples were collected from each beach (depending on the length), 3 were collected from the dry beach while the fourth was collected from the shoreline. These samples were tested in laboratory, where the $\mathrm{D}_{50}$ was obtained (UNE-EN 933-1: 2012; (Román-Sierra et al., 2013; Syvitski, 2007)). ii) Sedimentological data obtained from Ecolevante (2006). For each of the profiles analysed, the nearest samples were used.

\subsection{Modelling}

Initially, linear models were studied considering all the variables, for which the backwards method was applied. Starting with a linear model of 8 explanatory variables, they were eliminated one by one. All models had a bad fit and explain only $2.9 \%$ of the data at most. This indicates that there are no linear relationships between the DoC obtained by sediment method Aragonés et al. (2018) and the explanatory variables considered. Therefore, it is necessary to analyse non-linear relationships in which the DoC can be studied with the fewest number of variables that are easy to obtain.
Prior to the generation of the numerical models, a correlation study was carried out to see the influence of each of the variables on the DoC. Given that the values obtained in the study of correlations between the different variables and the DoC are very weak (0.0-0.2), three models with different input variables were generated to include or discard variables:

1 M1: This model includes only the factors related to wave energy: the wave height $\mathrm{H}_{\mathrm{s}, 12}$ and the period (T) associated with the mean flow, as well as the angle $(\alpha)$, in absolute value, that forms the mean flow with respect to the studied profile.

2 M2: In this model, the influence of sediment is added to model M1, so the variable $\mathrm{D}_{50}$ is added.

3 M3: Finally, the possible influence of $P$. oceanica is added, including in the M2 model the energy reduction coefficient $\left(\mathrm{K}_{\mathrm{v}}\right)$.

The numerical models were generated according to the methodology developed in Navarro-González and Villacampa (2016). This methodology is based on Galerkin's formulation of the finite element method (Hatami, 2018; Zienkiewicz et al., 2005) and makes it possible to obtain models of representation of a priori defined relationships between variables. It is a numerical methodology that improves the computational efficiency of the algorithms of the numerical methodologies used by the authors in other research (Aragonés et al., 2017; Aragonés et al., 2016b; Navarro-González and Villacampa, 2016; Navarro-González and Villacampa, 2012). They all have in common that they are based on the generation of a finite element geometric model (Villacampa et al., 2009) on which the methodology is defined. Therefore, for each finite element or meshing model defined in a hyper-cube, a model is generated. As usual, each finite element mesh is determined by its complexity which is defined as the number of elements defined at each edge of the hypercube. Consequently, for each data set (M1, M2 and M3) model families are generated from the selected complexity. The use of Galerkin's formulation of the finite element method and the corresponding improvement in computational efficiency allows us to analyse relationships in which a greater number of variables are involved without this implying a great deal of time in the execution of the software.

To evaluate the performance of each model, the following statistical errors were used: mean absolute percentage error (MAPE, Eq. (1)), absolute error (Eq. (2)), and relative percentage error (Eq. (3)).

$$
\begin{aligned}
& \text { MAPE }=\frac{1}{N} \sum_{i=1}^{N}\left|\frac{a^{i}-d^{i}}{a^{i}}\right| \\
& \varepsilon=\sqrt{\frac{\sum_{i=1}^{N}\left(a^{i}-d^{i}\right)^{2}}{N-p}}
\end{aligned}
$$

$$
\delta=\frac{\varepsilon}{\sqrt{\frac{1}{\mathrm{~N}} \sum_{\mathrm{i}=1}^{\mathrm{N}}\left(\mathrm{a}^{\mathrm{i}}\right)^{2}}}
$$

Finally, the models with the best results were validated. On the one hand, 19 profiles from outside the study area were used, specifically from the province of Almeria (Spain). On the other hand, the stability of the models was analysed. For the study of the stability of the models, random perturbations of $5 \%$ in the experimental data were carried out, analysing the variations generated in the models. 


\section{Results}

Firstly, before carrying out the study of variables and the generation of models, a study of outliers of the DoC is carried out. Thus, as shown in Fig. 2, data with values below $-9 \mathrm{~m}$ are discarded as outliers. The study of these points revealed that they were values obtained from profiles found in rocky areas or very close to river or ravines mouths, so they did not have the same characteristics as the rest of values in the study area. Therefore, they could not be represented by a model due to the low number of values with these characteristics. A total of 11 samples are involved, so the rest of the studies will be carried out with 438 profiles.

Secondly, a correlation study was carried out between the different variables analysed and the DoC. The variables also included the value of $\mathrm{H}_{\mathrm{s}, 12}$ multiplied by $\mathrm{K}_{\mathrm{v}}\left(\mathrm{H} \cdot \mathrm{K}_{\mathrm{v}}\right)$ and this multiplied by the cosine of the angle between the mean flow and the profile $\left(\mathrm{H} \cdot \mathrm{K}_{\mathrm{v}} \cdot \cos (\alpha)\right)$. As can be seen in Table 1, the correlations between the different variables and the DoC are very weak according to the Evans (1996) scale. Some weak correlations are observed between some variables such as wave height and angle of incidence and other very strong relationships such as between the energy reduction factor $\left(\mathrm{K}_{\mathrm{V}}\right)$ and $\mathrm{H} \cdot \mathrm{K}_{\mathrm{v}}$ and $\mathrm{H} \cdot \mathrm{K}_{\mathrm{v}} \cdot \cos (\alpha)$ as is normal as one is a combination of the other. Nor is there any relationship even though the variables are grouped by range.

Given the results obtained in the correlations, models with different input variables were generated. Firstly, a model is generated that only includes the variables referring to wave energy (M1) in order to compare with the current models. Secondly, the variable referring to sediment $\left(\mathrm{D}_{50}\right)$ is added, and it is noted that this model (M2) considerably improves (up to $20 \%$ ) the results obtained by the first model (M1), regardless of the complexity used (Fig. 3). Finally, a third model (M3) was generated that includes $\mathrm{K}_{\mathrm{v}}$ to analyse its real effect

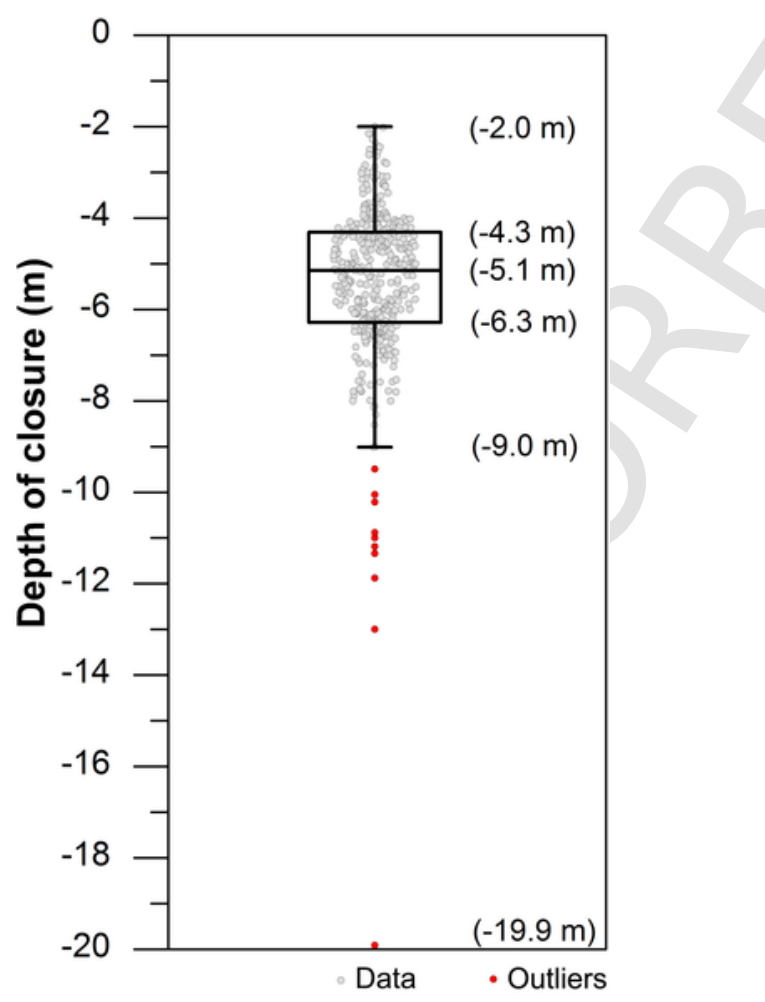

on DoC, although 240 of the profiles used do not present $P$. oceanica and the correlation obtained is very weak $(\mathrm{R}=0.015)$. Thus, the models improve considerably the accuracy of DoC when the variable $\mathrm{K}_{\mathrm{v}}$ is added for values of complexity $<100$. However, from complexity 150 , when both models (M2 and M3) reach an $R^{2}$ of 0.8 , there is practically no difference in the goodness of the fit.

If MAPE and absolute error are analysed (Fig. 4), it is observed that as the complexity of the models increases, the errors decrease being very similar for the M2 and M3 models. From a complexity of 90, for these two models the MAPE is $<10 \%$ (Fig. 4a), while the absolute error is $<40 \mathrm{~cm}$ from complexity 110 (Fig. 4b). If the results obtained are also compared with the most commonly used models currently in use (Hallermeier (1978) and Birkemeier (1985) empirical formulas), the errors are much higher than those made by the numerical models. The absolute error is $>1.2 \mathrm{~m}$ for Birkemeier and $1.6 \mathrm{~m}$ for Hallermeier, and MAPE is $>25 \%$ and $35 \%$, respectively.

Given that the errors of the M2 and M3 models are very similar, and considering the values of $\mathrm{R}^{2}$, in an attempt to select the best model, the absolute errors committed in each analysed profile are compared for the complexities between 130 and 300 (Table 2). It is decided to evaluate the number of points with minor and major errors of $0.5 \mathrm{~m}$, as well as the number of points with errors $>1 \mathrm{~m}$, and the mean error of each data set is obtained. Analysing the number of points in each of the observed ranges, it is observed that in all the complexities of the M2 and M 3 models, $>80 \%$ of the data show errors of $<0.5 \mathrm{~m}$. In addition, from complexity $150<20 \%$ of the points have errors $>0.5 \mathrm{~m}$ and $<10 \%$ have errors $>1.0 \mathrm{~m}$. However, when comparing the results obtained for the M2 and M3 models, they are very similar for all complexities. Although the mean absolute error for points with errors below $0.5 \mathrm{~m}$ is slightly lower for the M2 model, the number of data in this range is also somewhat lower, and in the other two ranges $(\varepsilon>0.5 \mathrm{~m}$ and $\varepsilon>1.0 \mathrm{~m})$ the error is slightly higher than for the M3 model. It is also observed that for complexities $>200$ the mean absolute error of those points increases, although the number of points in the range $\varepsilon>1.0 \mathrm{~m}$ decreases for the M2 model. Therefore, given the small difference $(\approx 2 \mathrm{~cm})$ between both models (M2 and M3), to select one or the other it is necessary to check the results obtained in the validation.

Since for the M2 and M3 models $\mathrm{R}^{2}$ values higher than 0.8 are reached from the complexity of 130, and the errors obtained for both models are very similar, it was decided to validate only the M2 model since it presents a lower number of input variables. Thus, Fig. 5 shows the average errors made during validation for the complexities of 130 , 140, 150 and 200. As complexity increases, errors increase. Consequently, it is better to use models of low complexity if what is wanted is to infer different data from those used to generate the models. The errors for complexity 130 and 140 are very similar, with the mean absolute error being $0.48-0.49 \mathrm{~m}$. MAPE and relative percentage error are very similar in the order of $14 \%$. The errors made in each of the validation profiles can be seen in Supplementary material 1.

Finally, to be able to choose between the M2 models of complexity 130 and 140, the stability of both models was studied. For this purpose, the results of disturbing the input variables of the M2 model by $5 \%$ randomly were analysed. Fig. 6 shows the absolute error and MAPE for each of the 10 disturbances performed. Thus, the mean absolute error obtained from the disturbances is $0.51 \pm 0.01 \mathrm{~m}$ (Fig. 6a) for both models, and MAPE is $14.97 \pm 0.80 \%$ for complexity 130 and $14.93 \pm 0.80 \%$ for complexity 140 (Fig. 6b). Both models are very similar with high stability, so the model with less complexity is chosen as usual, since the less complexity the fewer operations and execution time. Therefore, the model chosen is the M2 of complexity 130 . 
Table 1

Table of bivariate correlations.

\begin{tabular}{|c|c|c|c|c|c|c|c|c|}
\hline & & $\alpha$ & $H_{s, 12}$ & $T$ & $D_{50}$ & $\mathrm{~K}_{\mathrm{v}}$ & $\mathrm{H} \cdot \mathrm{K}_{\mathrm{v}}$ & $\mathrm{H} \cdot \mathrm{K}_{\mathrm{v}} \cdot \cos (\alpha)$ \\
\hline \multirow[t]{3}{*}{ DoC } & $\mathrm{R}$ & 0.014 & 0.026 & -0.050 & -0.093 & 0.015 & 0.014 & -0.004 \\
\hline & $R^{2}$ & 0.000 & 0.001 & 0.002 & 0.009 & 0.000 & 0.000 & 0.000 \\
\hline & Sig. (bi) & 0.772 & 0.594 & 0.300 & 0.051 & 0.760 & 0.773 & 0.928 \\
\hline \multirow[t]{3}{*}{$\alpha$} & $R$ & 1.000 & $0.629 *$ & $0.333^{*}$ & $-0.140^{*}$ & 0.092 & $0.298^{*}$ & $0.204^{*}$ \\
\hline & $R^{2}$ & 1.000 & 0.396 & 0.111 & \begin{tabular}{|l|}
0.020 \\
\end{tabular} & 0.009 & 0.089 & 0.042 \\
\hline & Sig. (bi) & - & 0.000 & 0.000 & 0.003 & 0.054 & 0.000 & 0.000 \\
\hline \multirow[t]{3}{*}{$H_{s, 12}$} & $\mathrm{R}$ & $0.629^{*}$ & 1.000 & $0.202^{*}$ & $-0.306^{*}$ & $0.170^{*}$ & $0.525^{*}$ & $0.436^{*}$ \\
\hline & $R^{2}$ & 0.396 & 1.000 & 0.041 & 0.094 & 0.029 & 0.276 & 0.190 \\
\hline & Sig. (bi) & 0.000 & - & 0.000 & 0.000 & 0.000 & 0.000 & 0.000 \\
\hline \multirow[t]{3}{*}{$\bar{T}$} & $R$ & $0.333^{*}$ & $0.202^{*}$ & 1.000 & -0.040 & -0.052 & 0.019 & -0.010 \\
\hline & $R^{2}$ & 0.111 & 0.041 & 1.000 & 0.002 & 0.003 & 0.000 & 0.000 \\
\hline & Sig. (bi) & 0.000 & 0.000 & - & 0.407 & 0.277 & 0.692 & 0.842 \\
\hline \multirow[t]{3}{*}{$D_{50}$} & $R$ & $-0.140^{*}$ & $-0.306^{*}$ & -0.040 & 1.000 & $-0.215^{*}$ & $-0.297^{*}$ & $-0.305^{*}$ \\
\hline & $R^{2}$ & 0.020 & 0.094 & 0.002 & 1.000 & 0.046 & 0.088 & 0.093 \\
\hline & Sig. (bi) & 0.003 & 0.000 & 0.407 & - & 0.000 & 0.000 & 0.000 \\
\hline \multirow[t]{3}{*}{$\mathbf{K}_{\mathrm{v}}$} & $\begin{array}{ll}R \\
\end{array}$ & 0.092 & $0.170^{*}$ & -0.052 & $-0.215^{*}$ & 1.000 & $0.911^{*}$ & $0.921^{*}$ \\
\hline & $R^{2}$ & 0.009 & 0.029 & 0.003 & 0.046 & 1.000 & 0.830 & 0.848 \\
\hline & Sig. (bi) & 0.054 & 0.000 & 0.277 & 0.000 & - & 0.000 & 0.000 \\
\hline \multirow[t]{3}{*}{$\mathrm{H} \cdot \mathrm{K}_{\mathrm{v}}$} & $R$ & $0.298^{*}$ & $0.525^{*}$ & 0.019 & $-0.297^{*}$ & $0.911^{*}$ & 1.000 & $0.977^{*}$ \\
\hline & $R^{2}$ & 0.089 & 0.276 & 0.000 & 0.088 & 0.830 & 1.000 & 0.955 \\
\hline & Sig. (bi) & 0.000 & 0.000 & 0.692 & 0.000 & 0.000 & - & 0.000 \\
\hline \multirow[t]{3}{*}{$\mathrm{H} \cdot \mathrm{K}_{\mathrm{v}} \cdot \cos (\alpha)$} & \begin{tabular}{|l|}
$R$ \\
\end{tabular} & $0.204^{*}$ & $0.436^{*}$ & -0.010 & $-0.305^{*}$ & 0.921* & $0.977^{*}$ & 1.000 \\
\hline & \begin{tabular}{|l|}
$R^{2}$ \\
\end{tabular} & 0.042 & 0.190 & 0.000 & 0.093 & 0.848 & 0.955 & 1.000 \\
\hline & Sig. (bi) & 0.000 & 0.000 & 0.842 & 0.000 & 0.000 & 0.000 & - \\
\hline
\end{tabular}

*The correlation is significant at the 0.01 level (bilateral).

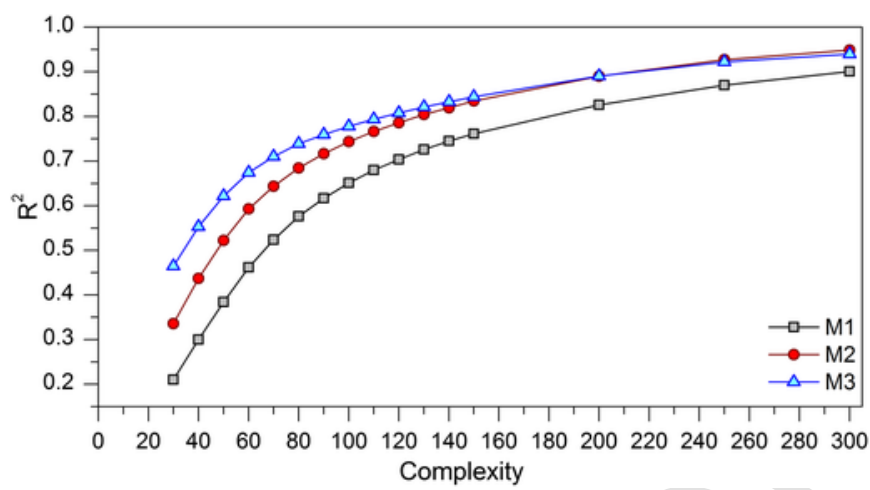

Fig. 3. $\mathrm{R}^{2}$ values for the different models generated.

\section{Discussion}

Sandy beaches serve two purposes: i) protect the coast, and ii) as leisure areas where people enjoy the sun and the sea. However, this type of beach is in continuous erosion as a consequence of the lack of sand supply from rivers and ravines (Newton et al., 2012; Pagán et al., 2017), or from anthropogenic actions generated in its surroundings (Aragonés et al., 2015; Pagán et al., 2016). Therefore, if we want to protect all those assets located behind the sandy beaches and at the same time continue to have a leisure area with high economic value in many of today's societies, it is necessary to make nourishments. For this purpose, the coastal engineer needs to accurately calculate the equilibrium beach profile (EBP) and its lower limit, the depth of closure (DoC). The variations that occur in the EBP over time are very small, even though the beach is in erosion or accretion, as long as the beach sediments have not changed (Aragonés et al., 2016a). Therefore, precise methods to determine the DoC are needed to avoid errors in the calculation of the sand volume for a nourishment.

The most precise methods currently available for the determination of the depth of closure consist mainly of the continuous collection of cross-shore profiles. It is also possible to obtain this limit from sediment samples at different depths. However, the use of these methods (profiles or sediment) requires a long period of time and/or large economic investment. Although the relationships in the coastal on-shore zone are complex (Table 1), tools are available today that have not yet been put in the hands of the coastal engineer. Thus, it can be seen how mathematical formulations (Hallermeier and Birkemeier's formulation) are still being used to obtain the DoC from other variables related, generally, to the waves and that do not provide sufficient precision when determining the position of a coastal work or the volume of sand required for a beach nourishment, which generates important variations in the width of the beach with respect to those foreseen in the project. Therefore, in this paper, a numerical model and a method are generated with which sufficient precision is obtained for the determination of the $\mathrm{DoC}$, and at the same time requires a minimum investment. Since the variables used (Table 1) are generally available in most of the administrations of the different countries or are indispensable and necessary to obtain them before any beach nourishment project.

To be able to generate the model, known DoC data, obtained from the sediment sampling method developed by Aragonés et al. (2018), were used. This method presents high precision, simplicity, a long validity period and less sensitivity to changes as a result of anthropogenic actions to obtain the DoC. From a GIS system and information from 5029 sediment samples collected in the Ecolevante (2006) and EcoMAG (2009), the DoC was obtained for each of the profiles studied. 


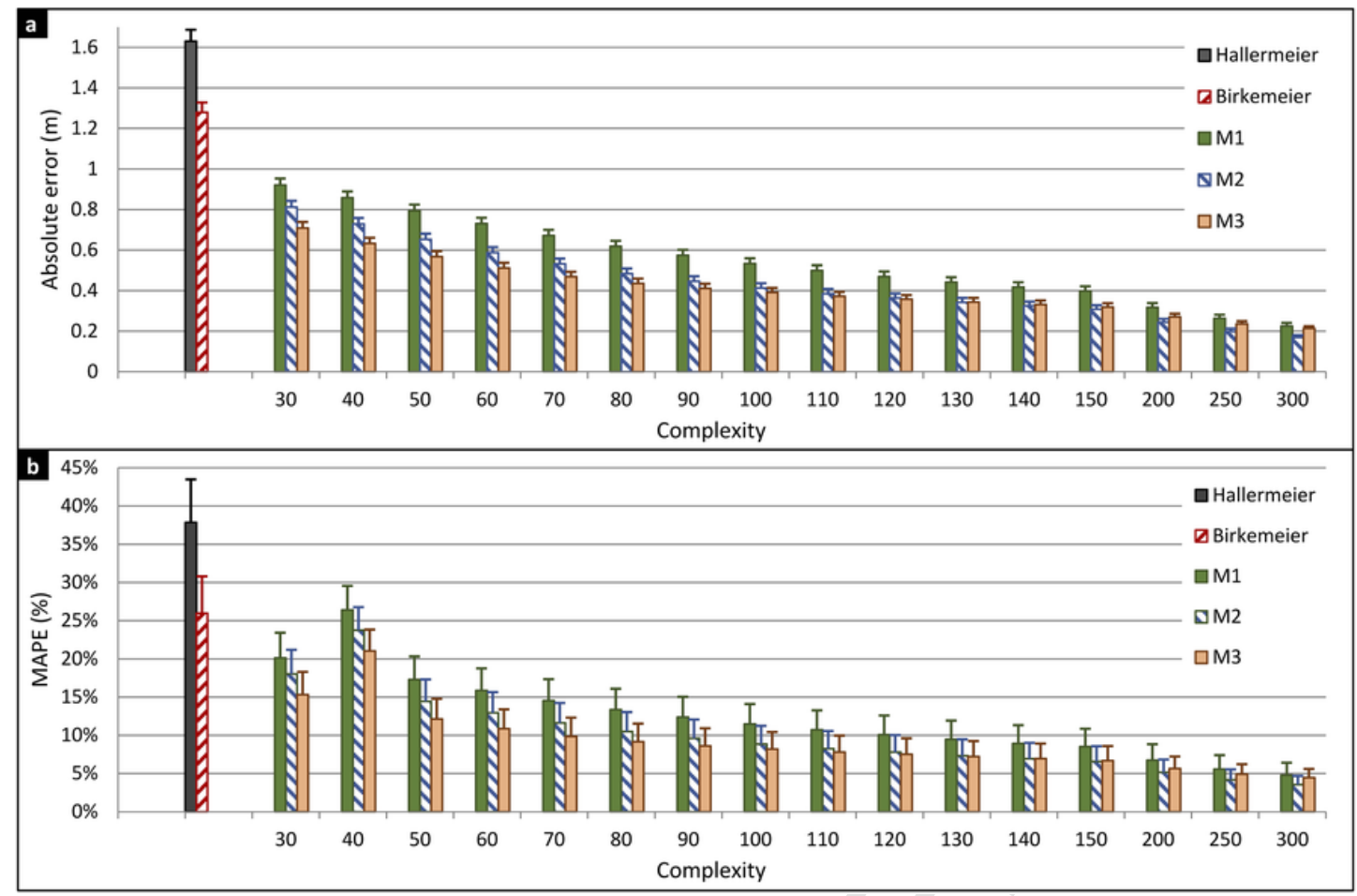

Fig. 4. a) MAPE and b) absolute error.

Table 2

Number of points and mean absolute error made by the dataset for each of the error ranges $(\varepsilon \leq 0.5 \mathrm{~m}, \varepsilon>0.5 \mathrm{~m}$ and $\varepsilon>1.0 \mathrm{~m})$.

\begin{tabular}{|c|c|c|c|c|c|c|c|c|}
\hline Complexity & & & 130 & 140 & 150 & 200 & 250 & 300 \\
\hline \multirow[t]{6}{*}{$\varepsilon \leq 0.5 \mathrm{~m}$} & \multirow[t]{2}{*}{ M1 } & N (\%) & $299(68.6 \%)$ & $309(70.9 \%)$ & $316(72.5 \%)$ & $342(78.4 \%)$ & $358(82.1 \%)$ & $373(85.6 \%)$ \\
\hline & & Error (m) & 0.16 & 0.16 & 0.15 & 0.13 & 0.11 & 0.11 \\
\hline & \multirow[t]{2}{*}{ M2 } & $\mathrm{N}(\%)$ & $340(78.0 \%)$ & $352(80.7 \%)$ & $353(81.0 \%)$ & $368(84.4 \%)$ & $385(88.3 \%)$ & $398(91.3 \%)$ \\
\hline & & Error (m) & 0.14 & 0.15 & 0.14 & 0.12 & 0.11 & 0.11 \\
\hline & \multirow[t]{2}{*}{ M3 } & $\mathrm{N}(\%)$ & $345(79.1 \%)$ & $349(80.0 \%)$ & $355(81.4 \%)$ & $372(85.3 \%)$ & $384(88.1 \%)$ & $397(91.1 \%)$ \\
\hline & & Error (m) & 0.16 & 0.16 & 0.16 & 0.16 & 0.15 & 0.15 \\
\hline \multirow[t]{6}{*}{$\varepsilon>0.5 \mathrm{~m}$} & \multirow[t]{2}{*}{ M1 } & $\mathrm{N}(\%)$ & $137(31.4 \%)$ & $127(29.1 \%)$ & $120(27.5 \%)$ & $94(21.6 \%)$ & $78(17.9 \%)$ & $63(14.4 \%)$ \\
\hline & & Error (m) & 1.05 & 1.05 & 1.05 & 1.02 & 0.95 & 0.92 \\
\hline & \multirow[t]{2}{*}{ M2 } & $\mathrm{N}(\%)$ & $96(22.0 \%)$ & $84(19.3 \%)$ & $83(19.0 \%)$ & $68(15.6 \%)$ & $51(11.7 \%)$ & $38(8.7 \%)$ \\
\hline & & Error (m) & 1.06 & 1.10 & 1.06 & 0.96 & 0.87 & 0.82 \\
\hline & \multirow[t]{2}{*}{ M3 } & $\mathrm{N}(\%)$ & $91(20.9 \%)$ & $87(20.0 \%)$ & $81(18.6 \%)$ & $64(14.7 \%)$ & $52(11.9 \%)$ & $39(8.9 \%)$ \\
\hline & & Error (m) & 1.04 & 1.03 & 1.03 & 0.94 & 0.85 & 0.82 \\
\hline \multirow[t]{6}{*}{$\varepsilon>1.0 \mathrm{~m}$} & \multirow[t]{2}{*}{ M1 } & $\mathrm{N}(\%)$ & $55(12.6 \%)$ & $53(11.8 \%)$ & $52(11.6 \%)$ & $37(8.2 \%)$ & $28(6.2 \%)$ & $17(3.8 \%)$ \\
\hline & & Error (m) & 1.52 & 1.50 & 1.47 & 1.44 & 1.38 & 1.41 \\
\hline & \multirow[t]{2}{*}{ M2 } & $\mathrm{N}(\%)$ & $46(10.6 \%)$ & $43(9.6 \%)$ & $42(9.4 \%)$ & $27(6.0 \%)$ & $12(2.7 \%)$ & $6(1.3 \%)$ \\
\hline & & Error (m) & 1.44 & 1.42 & 1.38 & 1.29 & 1.31 & 1.38 \\
\hline & \multirow[t]{2}{*}{ M3 } & $\mathrm{N}(\%)$ & $44(10.1 \%)$ & $42(9.4 \%)$ & $38(8.5 \%)$ & $22(4.9 \%)$ & $14(3.1 \%)$ & $10(2.2 \%)$ \\
\hline & & Error (m) & 1.40 & 1.37 & 1.37 & 1.35 & 1.29 & 1.27 \\
\hline
\end{tabular}

The study area (Fig. 1) is a complex zone and the beaches analysed have different orientations, which makes the waves different from one another. From the different input variables studied, it has been observed that the correlations between them are very low (Table 1), which led us to believe that the relationship between the different variables and the DoC did not follow a linear relationship, which was later confirmed by the results of the linear models $\left(\mathrm{R}^{2}<3 \%\right)$. That is why 3 numerical models were made using different variables. From the results of the models, the greater the complexity of the model, the greater the $\mathrm{R}^{2}$. However, the model chosen must be valid for different zones and with different values in the input variables. That is why, in addition to considering the adjustment $\left(\mathrm{R}^{2}\right)$, the errors of the models (MAPE and absolute error) were analysed to select the best model. Moreover, the stability of the models against $5 \%$ disturbance in the experimental data was analysed. The results of the M2 and M3 models are practically the same (Fig. 4). Since the only methodological difference is the inclusion of the $\mathrm{K}_{\mathrm{v}}$ due to the $P$. oceanica in M3, it can be stated that the DoC obtained as an independent variable from sedimentological data already consider the influence of this marine phanerogam. Therefore, the model with the lowest number of dependent variables (M2) has been chosen, which implies the least time and cost in data collection, being the models of complexity 130-200 the ones selected to carry out the validation.

An important aspect of a model is to check whether it improves the results obtained by models commonly used by coastal engineers. In this work, Galerkin's formulation of the finite element method according to the methodology developed at Navarro-González and Villacampa (2016) was used to reduce computational time given the 


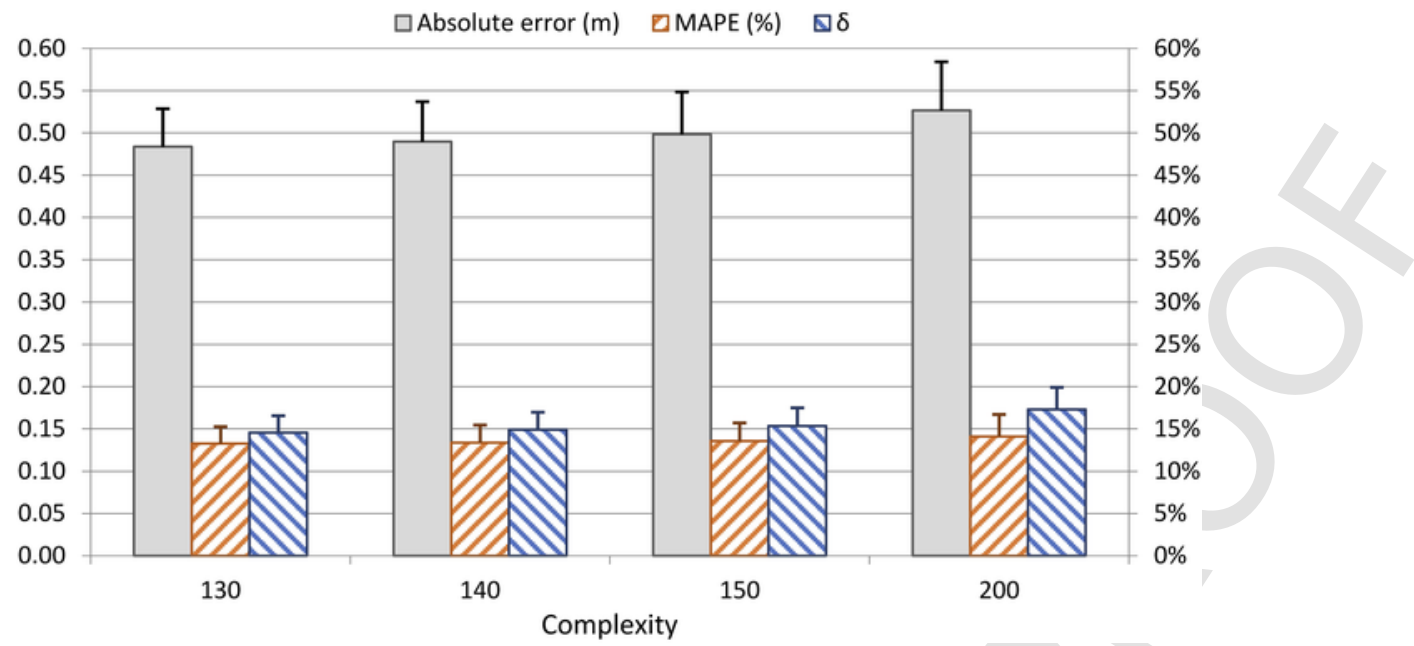

Fig. 5. Average errors made during validation in 19 profiles in Almería.

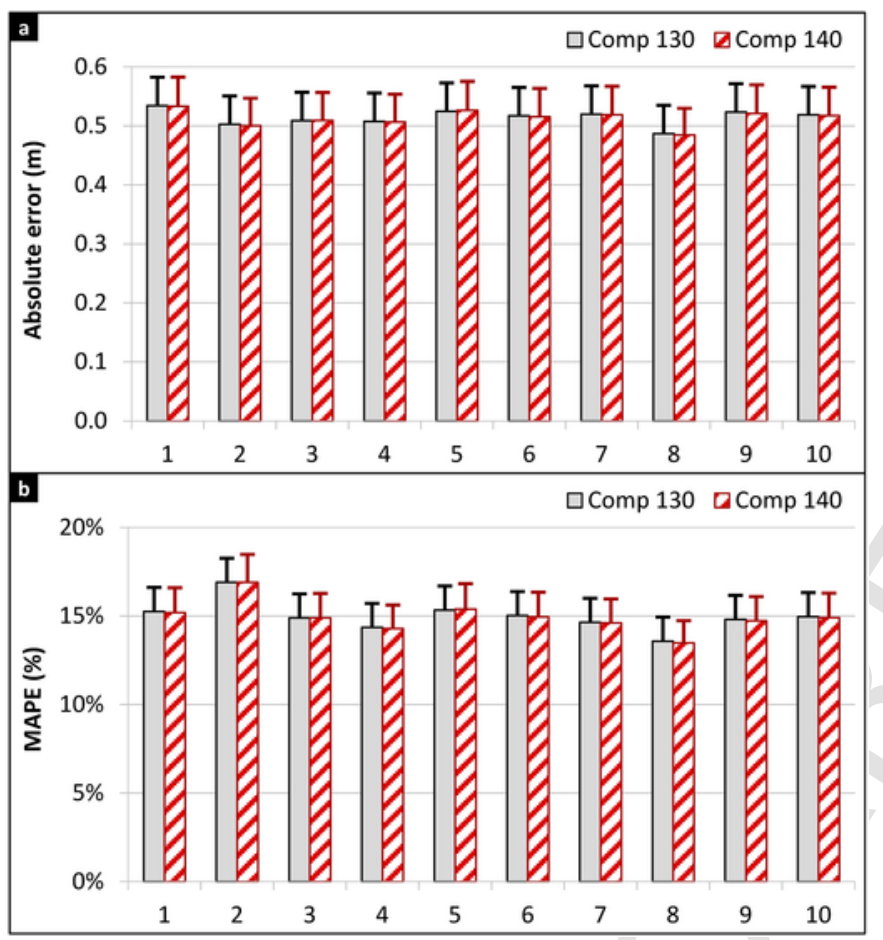

Fig. 6. a) Mean absolute error and b) mean MAPE for the 10 disturbances of $5 \%$ of all variables.

large amount of data used and generate highly complex models. Thus, Fig. 4 shows that the selected models improve by $71 \%$ and $80 \%$ the results obtained by the usual formulations of Birkemeier (1985) and Hallermeier (1978), respectively. Likewise, any model chosen must be able to be used outside the study area. In effect, the analysis of the validation with 19 profiles from Almeria for the M2 model and 130 and 140 complexities, gives a MAPE somewhat higher than $13 \%$ and an absolute error of $0.65 \mathrm{~m}$ (Fig. 5), slightly higher than the average obtained by the model but much lower than the current models..

Finally, in order to be able to choose between the M2 models of complexity 130 and 140 , the stability of both models against random perturbations in the experimental data of the input or explanatory variables was studied. This study is performed by varying all the input variables of the M2 for complexities of 130 and 140 chosen. The input variables are disturbed randomly by $5 \%$, since it is understood that these variables due to data collection errors or variability in areas with similar characteristics to those studied may vary in that range. The results obtained for both complexities are very similar, MAPE slightly worse, reaching around $14.9 \%$. This value is not considered excessive since this parameter measures the relative error being $14 \%$ a permissible value. As for the absolute error, of $0.51 \mathrm{~m}$, it represents an increase with respect to the MAPE model of $7.4 \%$ and $0.15 \mathrm{~m}$ (Fig. 6)

Therefore, complex areas such as the ones we are dealing with have been examined with a different approach to the traditional one, with the use of tools in which the changes can be analysed in 3D (spatial and temporal). Thus, from this study, mathematical models have been proposed that have been validated and compared with the current ones. These models will implicitly have in their essence a local character of the samples and the environment in which they have been studied, but their methodology can be extrapolated to other coastal environments around the world.

\section{Conclusion}

In this paper a numerical model based on Galerking's formulation of the finite element method has been developed, which allows to reduce the computation time and to generate families of numerical models with high complexity. Among the different models generated it can be stated that:

- The inclusion of the energy reduction coefficient among the input variables has little influence on the improvement of model performance.

- The most influential variables for the determination of DoC are the wave energy on the beach and the type of sediment.

- The model chosen could be used in other study areas where the characteristics are similar to those studied here, and remains stable for variations of around $5 \%$.

- The results of the model are MAPE $<7.5 \%$ and absolute error $<0.36 \mathrm{~m}$, which improves the current models (Birkemeier and Hallermeier) by $71 \%$ and $80 \%$, respectively.

The most commonly used methods to evaluate DoC require either many years of surveys, such as beach profiles, or expensive sampling campaigns, as sediment-based methods. The proposed method in this 
work improves the currently methods, requires less investment and uses easily obtainable parameters.

Supplementary data to this article can be found online at https:// doi.org/10.1016/j.scitotenv.2019.01.017.

\section{Acknowledgments}

Authors thank Dirección General de Costas (Ministerio de Agricultura y Medio Ambiente), Universidad de Alicante and Puertos del Estado for providing access to their data.

This work was partially supported by the Universidad de Alicante through the project "Estudio sobre el perfil de equilibrio y la profundidad de cierre en playas de arena" (GRE15-02).

\section{References}

Allen, J.R., 1981. Beach erosion as a function of variations in the sediment budget, Sandy Hook, New Jersey, U.S.A. Earth Surf. Process. Landf. 6 (2), 139-150.

Aragonés, L., García-Barba, J., García-Bleda, E., López, I., Serra, J., 2015. Beach nourishment impact on Posidonia oceanica: case study of Poniente Beach (Benidorm, Spain). Ocean Eng. 107, 1-12.

Aragonés, L., Serra, J.C., Villacampa, Y., Saval, J.M., Tinoco, H., 2016. New methodology for describing the equilibrium beach profile applied to the Valencia's beaches. Geomorphology 259, 1-11.

Aragonés, L., Villacampa, Y., Navarro-González, F.J., López, I., 2016. Numerical modelling of the equilibrium profile in Valencia (Spain). Ocean Eng. 123, 164-173.

Aragonés, L., López, I., Villacampa, Y., Navarro-González, F.J., 2017. Using the presence of seagrass Posidonia oceanica to model the equilibrium profile parameter A of sandy beaches in Spain. J. Coast. Res. 33 (3), 642-652.

Aragonés, L., Pagán, J.I., López, I., Serra, J.C., 2018. Depth of closure: new calculation method based on sediment data. Int. J. Sediment Res. 33 (2), 198-207.

Birkemeier, W.A., 1985. Field data on seaward limit of profile change. J. Waterw. Port Coast. Ocean Eng. 111 (3), 598-602.

Crain, D.A., Bolten, A.B., Bjorndal, K.A., 1995. Effects of beach nourishment on sea turtles: review and research initiatives. Restor. Ecol. 3 (2), 95-104.

Dean, R.G., 2002. Beach Nourishment: Theory and Practice. World Scientific Publishing, Singapore, 399

Dean, R.G., Healy, T.R., Dommerholt, A.P., 1993. A "blind-folded" test of equilibrium beach profile concepts with New Zealand data. Mar. Geol. 109 (3), 253-266.

Dette, H.H., Larson, M., Murphy, J., Newe, J., Peters, K., Reniers, A., Steetzel, H., 2002. Application of prototype flume tests for beach nourishment assessment. Coast. Eng. 47 (2), 137-177.

Ecolevante, 2006. Estudio ecocartográfico del litoral de las provincias de Alicante y Valencia. Dirección General de Costas, Ministerio de Medio Ambiente, Spain, Available online: http://www.mapama.gob.es/es/costas/temas/proteccion-costa/ ecocartografias/ecocartografia-alicante.aspx, (pp.).

Ecomag, 2009. Estudio ecocartográfico de las provincias de Granada, Almería y Murcia. Dirección General de Costas, Ministerio de Medio Ambiente, Spain, Available online: http://www.mapama.gob.es/es/costas/temas/proteccion-costa/ ecocartografias/ecocartografia-murcia.aspx, (pp.).

Evans, J.D., 1996. Straightforward Statistics for the Behavioral Sciences. Brooks/Cole, (pp.).

Folk, R.L., Ward, W.C., 1957. Brazos River bar: a study in the significance of grain size parameters. J. Sediment. Petrol. 27, 3-26.

Garcia, N., Masselink, G., Scott, T., Conley, D., 2017. Depth of closure along an embayed, macro-tidal and exposed coast: a multi-criteria approach. In: Coastal Dynamics 2017, (Elsinore, Denmark).

Hallermeier, R.J., 1978. Uses for a calculated limit depth to beach erosion. In: Proceedings of the Proceedings of the 16th Coastal Engineering Conference (Hamburg, Germany). pp. 1493-1512.
Hallermeier, R.J., 1981. Seaward limit of significant sand transport by waves: an annual zonation for seasonal profiles. In: DTIC Document.

Hamm, L., Capobianco, M., Dette, H., Lechuga, A., Spanhoff, R., Stive, M., 2002. A summary of European experience with shore nourishment. Coast. Eng. 47 (2), 237-264.

Hatami, M., 2018. Weighted Residual Methods. Academic Press, 384.

Hinton, C., Nicholls, R.J., 1998. Spatial and temporal behaviour of depth of closure along the Holland Coast. In: Proceedings of the Proceedings of 26th International Conference on Coastal Engineering (Copenhagen, Denmark). pp. 2913-2925.

Koftis, T., Prinos, P., 2012. Estimation of wave attenuation over Posidonia oceanica. In: Mitteilungen des Lehrstuhls und Instituts für Wasserbau und Wasserwirtschaft der Rheinisch-Westfälischen Technischen Hochschule Aachen. 165.

Larson, M., Hanson, H., 1996. Schematized numerical model of three-dimensional beach change. In: Proceedings of 10th Congress of the IAHR Asia and Pacific Division. vol. 2, pp. 325-332.

Marsh, S.W., Nicholls, R.J., Kroon, A., Hoekstra, P., 1998. Assessment of depth of closure on a nourished beach: Terschelling, the Netherlands. In: ASCE (Ed.), International Conference on Caostal Engineering, (Reston, VA).

Mendez, F.J., Losada, I.J., 2004. An empirical model to estimate the propagation of random breaking and nonbreaking waves over vegetation fields. Coast. Eng. 51 (2), 103-118.

Navarro-González, F.J., Villacampa, Y., 2012. A new methodology for complex systems using n-dimensional finite elements. Adv. Eng. Softw. 48 (1), 52-57.

Navarro-González, F.J., Villacampa, Y., 2016. A finite element numerical algorithm for modelling and data fitting in complex systems. Int. J. Comput. Methods Exp. Meas. 4 (1), 100-113.

Newton, A., Carruthers, T.J.B., Icely, J., 2012. The coastal syndromes and hotspots on the coast. Estuar. Coast. Shelf Sci. 96, 39-47.

Nicholls, R.J., Birkemeier, W.A., Hallermeier, R.J., 1996. Application of the depth of closure concept. In: Proceedings of the 25th International Conference on Coastal Engineering (Reston, VA). pp. 3874-3887.

Nicholls, R.J., Birkemeier, W.A., Lee, G.H., 1998. Evaluation of depth of closure using data from Duck, NC, USA. Mar. Geol. 148 (3-4), 179-201.

Niedoroda, A.W., Swift, D.J.P., Hopkins, T.S., 1985. The shoreface. In: Davis, R.A. (Ed.), Coastal Sedimentary Environments. Springer-Verlag, New York, pp. 533-624.

Pagán, J.I., Aragonés, L., Tenza-Abril, A.J., Pallarés, P., 2016. The influence of anthropic actions on the evolution of an urban beach: case study of Marineta Cassiana beach, Spain. Sci. Total Environ. 559, 242-255.

Pagán, J.I., López, I., Aragonés, L., Garcia-Barba, J., 2017. The effects of the anthropic actions on the sandy beaches of Guardamar del Segura, Spain. Sci. Total Environ. 601, 1364-1377.

Phillips, M.R., Williams, A.T., 2007. Depth of closure and shoreline indicators: empirical formulae for beach management. J. Coast. Res. 23 (2), 487-500.

Pranzini, E., Wetzel, L., Williams, A.T., 2015. Aspects of coastal erosion and protection in Europe. J. Coast. Conserv. 19 (4), 445-459.

Román-Sierra, J., Muñoz-Perez, J.J., Navarro-Pons, M., 2013. Influence of sieving time on the efficiency and accuracy of grain-size analysis of beach and dune sands. Sedimentology 60 (6), 1484-1497.

Semeoshenkova, V., Newton, A., 2015. Overview of erosion and beach quality issues in three southern European countries: Portugal, Spain and Italy. Ocean Coast. Manag. 118, 12-21.

Syvitski, J.P., 2007. Principles, Methods and Application of Particle Size Analysis. Cambridge University Press, Cambridge, UK, 368.

Trembanis, A.C., Pilkey, O.H., 1998. Summary of beach nourishment along the US Gulf of Mexico shoreline. J. Coast. Res. 14 (2), 407-417.

Villacampa, Y., Navarro-González, F.J., Llorens, J., 2009. A geometric model for the generation of models defined in Complex Systems. In: Ecosystems and Sustainable Development VII. pp. 71-82.

Walstra, D.J.R., Roelvink, J.A., Groeneweg, J., 2001. Calculation of wave-driven currents in a 3D mean flow model. In: Coastal Engineering Conference ASCE. vol. 2(1050-1063).

Zienkiewicz, O.C., Taylor, R.L., Zhu, J.Z., 2005. The Finite Element Method: Its Basis and Fundamentals. Elsevier Butterworth-Heinemann, 714. 